\title{
O QUE DIZ O PROFESSOR DA EDUCAÇÃO BÁSICA SOBRE A EXISTÊNCIA DO BULLYING NA ESCOLA INCLUSIVA
}

\author{
Branca Maria de Meneses \\ Rejane de Aquino Souza
}

\begin{abstract}
Resumo: Este trabalho se refere a um relato de experiência sobre a concepção do docente da educação básica a respeito da existência do bullying no ambiente escolar, especialmente, no que concerne ao aluno em situação de inclusão. Para isso, foram realizadas seis questões a um(a) professor(a) de Língua Portuguesa de uma escola pública municipal de Campo Grande-MS, sendo uma, exclusivamente, sobre a ocorrência de bullying contra aluno em situação de inclusão.
\end{abstract}

Palavras-chave: Concepção; violência; bullying, professor; educação básica.

Resumen: Este trabajo se refiere a un relato de experiencia sobre la concepción del docente de la educación básica acerca de la existencia del bullying en el ambiente escolar, especialmente, en lo que afecta al alumno en situación de inclusión. Para ello, se realizaron seis preguntas a un (a) profesor (a) de Lengua Portuguesa de una escuela público municipal de Campo Grande-MS, siendo una, exclusivamente, sobre la ocurrencia de bullying contra alumno en situación de inclusión.

Palabras-claves: Concepión; violencia; bullying; profesor; educación básica.

\section{Introdução}

Este trabalho tem como objetivo apresentar um relato de experiência a respeito da concepção de um(a) docente da educação básica sobre a existência do bullying no ambiente escolar, especialmente, em relação aos alunos em situação de inclusão.

Para isso, foram realizadas seis questões a um(a) professor(a) de Língua Portuguesa que atua há seis anos numa escola pública municipal de Campo Grande-MS,

\footnotetext{
* Professora Doutora do Programa de Mestrado em Psicologia da Universidade Federal de Mato Grosso do Sul e da Graduação em Psicologia da mesma instituição. Contato: brancameneses@yahoo.com.br

** Mestranda em Psicologia pela Universidade Federal de Mato Grosso do Sul. Atua efetivamente como docente no Campus de Aquidauana da mesma instituição. Contato: rejane.aquino-souza@ufms.br
}

sendo uma das questões, exclusivamente, sobre a ocorrência de bullying em relação aos alunos em situação de inclusão. As seis questões propostas foram: se o(a) docente já testemunhou casos de intimidação na escola que atua; quais seriam os motivos do bullying, caso já tenha testemunhado; as características dos alunos agressores e das vítimas, caso já tenha testemunhado; se os alunos em situação de inclusão sofrem bullying tanto quanto os demais alunos; o que seria necessário fazer para combater esse tipo de violência na escola; qual seria o papel das autoridades nesse combate.

Todo o processo foi realizado em dois encontros na própria escola onde o(a) professor(a) atua, sendo que no primeiro ocor-

MENESES, Branca Maria; SOUZA, Rejane de Aquino. O que diz o professor da educação básica sobre a existência do bullying na escola inclusiva. Revista Sul-Americana de Filosofia e Educação. Número 28: maio-out./2017, p. 156-164. 
reu o questionamento e o registro escrito das respostas do(a) colaborador(a) e, no segundo, a leitura e validação de suas respostas já digitadas.

Importa deixar claro que as questões utilizadas neste estudo fazem parte dos instrumentos de uma pesquisa sobre a violência escolar no bullying, de autoria de Crochík (2014). E ainda, que a base epistemológica deste trabalho concerne à Teoria Crítica da Sociedade e, especialmente, aos estudos de Crochík (2014).

\section{Fundamentação Teórica}

O termo bullying, segundo Crochík (2014), tem sido utilizado como sinônimo de intimidação e provocação, sendo compreendido como um tipo de violência praticado/sofrido entre as crianças e adolescentes em idade escolar. $\mathrm{O}$ autor explica que são atitudes hostis de um aluno ou de um grupo contra o alvo e que acontecem com frequência, podendo ocorrer por meio de atos diretos e físicos, diretos e verbais ou indiretos.

A violência, no interior das escolas, reflete a barbárie presente na sociedade, já que, de acordo com Adorno (1995), a educação faz parte da sociedade e seus membros também apresentam as características de regressão psíquica encontradas nos membros da sociedade.
Nos termos de Marcuse (1975), tal regressão tem sido mediada, intencionalmente, pela administração social de acordo com os ideais de dominação. Esse processo ocorre pela repressão e pelo uso da força de trabalho para o desempenho produtivo alienando os trabalhadores com a falsa promessa de que o progresso eliminaria a escassez de bens. Ocorre que a ideologia da racionalidade vigente, pautada na técnica, tem impactado na intensa redução da reflexão e da criticidade dos indivíduos, estabelecendo, além de outras consequências, a desindividuação e a indiferenciação entre os sujeitos, o que favorece a violência segundo Crochík (2011).

Crochík (2011) argumenta que pela ideologia da racionalidade tecnológica se estabelece na sociedade administrada uma uniformização do pensamento e do comportamento. Dessa maneira, os indivíduos são conduzidos à adaptação irracional ao coletivo, onde qualquer tipo de resistência ou de desvio do padrão estabelecido pode suscitar o preconceito, a discriminação e a violência. Ademais, o autor explica, também, sobre a formação reativa, isto é, o ataque sobre a própria fragilidade que o alvo suscita no agressor.

A esse respeito, Crochík (2014) discute sobre a questão da hierarquia das relações 
sociais e do trabalho presente também no interior do ambiente escolar, é a chamada hierarquia escolar: o fisicamente mais forte $e$ o mais fraco, o melhor e o pior nas notas, $e$ o mais e o menos popular. Conforme o autor, deve-se considerar, ainda, os alunos em situação de inclusão, que o são justamente por se constituírem em minorias, onde os mesmos são marginalizadas ou segregadas pelos demais alunos, sendo estes motivados, especialmente, pelo preconceito. Nessa perspectiva, os alunos inclusos também podem ser alvos de bullying. Antunes e Zuin (2008 apud CROCHÍK, 2014, p. 12) indicam que:

As vítimas do bullying têm sido: pessoas que têm características físicas, socioeconômica, étnica e preferência sexual específicas, entre eles, ciganos, artistas de circo, estrangeiros, alunos obesos, de baixa estatura, homossexuais. Se os alunos com deficiência física, sensorial e intelectual têm uma distinção perceptível em relação a outras pessoas, se essas diferenças são frutos da natureza ou de acidentes, os demais alvos podem apresentar características de fragilidade que são culturalmente desvalorizadas.

Crochík (2014) explica que os adultos têm concebido o bullying como uma mera brincadeira inofensiva, própria da infância, que serão superadas e que as próprias crianças resolverão. Entretanto, o autor diz que o bullying pode "gerar diversas consequências psíquicas no que o sofre, desde uma angústia acentuada até o assassinato e o suicídio" (p. 13), e os que praticam podem vir, inclusive, a ter envolvimento com a criminalidade.

Ao compreender que a escola reflete as características da sociedade administrada e de seus indivíduos, irracionalmente heterônomos, indiferenciados e desindividuados, a família, como parte da mesma sociedade, também traz esse reflexo. Isso porque a família pode influenciar seus filhos no aspecto da violência, ou por esta ocorrer no interior dos lares ou pela indiferença (negação) em relação à formação da consciência moral dos pequenos deixando essa responsabilidade, exclusivamente, para a escola. (CROCHÍK, 2014).

Dessas atribuições de causas, podemos supor duas tendências de pensamento no que se refere à autoridade educativa - familiar ou escolar: uma defende a imposição de limites de forma rígida; outra, ao contrário, negligencia a necessidade da indicação de limites pelos pais. Ambas, paradoxalmente, são semelhantes em seus efeitos: não possibilitam adequadamente a formação da consciência moral, nomeada pela psicanálise de superego; a primeira, porque ao mesmo tempo em que indica claramente o que a autoridade deva incutir às crianças $e$ aos jovens, o faz de maneira ambivalente e calcada no princípio e não em sua racionalidade: é pelo medo, segundo essa tendência, que as pessoas seguem os 
indicadores morais, e não por convicção, assim, essa consciência se forma fragilmente e se torna ambígua; a segunda, porque a autoridade não oferece nenhum modelo para que seus filhos se identifiquem $e$ assim o que se pode ou não fazer é dirigido externamente. (CROCHÍK, 2014, p. 18).

Assim, a formação da consciência moral não se relaciona com o autoritarismo que produz e reproduz preconceito e violência, mas sim, com a autoridade para o estabelecimento da autonomia.

\begin{abstract}
A autonomia deve se constituir na possibilidade de analisar e decidir sobre as próprias ações e escolhas com base na expressão adequada do próprio desejo e das condições adequadas para realizá-lo sem por em risco a si próprio e aos outros. Somente seguir regras, ou não segui-las indica heteronomia. (CROCHÍK, 2014, p. 19).
\end{abstract}

Ainda com as contribuições do mesmo autor a respeito do bullying, o que se nota, na realidade, refere-se à permanência de uma visão do ato no bullying em si mesmo, sem levar em conta a ideologia da racionalidade da técnica e a heteronomia predominantes na sociedade. Assim, são tomados, costumeiramente, duas atitudes por parte dos adultos, segundo Crochík (2014): a impunidade pelo discurso de que a criança ou o adolescente está em formação e que por isso não pode ser responsável por seus atos infracionais; e a pautada na concepção legalista com a responsabilização individual, isto é, a culpabilização exclusivamente à criança ou ao adolescente sobre os atos de intimidação e de agressividade. "Ambas, contudo, são idealistas, como contraposição ao materialismo e, certamente, não pensam o objeto por meio de suas contradições." (CROCHÍK, 2014, p. 20).

Tendo como base as conjecturas aqui apresentadas e por referência à Teoria Crítica da Sociedade, a próxima subseção diz respeito ao relato de experiência em articulação com o exposto acima.

\section{Relato e Discussões}

Este item está organizado propriamente pela sequência das questões realizadas com o(a) professor(a) colaborador(a) do estudo e com as suas respectivas respostas e, logo em seguida de cada questão e resposta, estão as discussões articuladas ao quadro de referências teóricas adotado.

Quando questionado(a) sobre se já havia testemunhado casos de bullying (intimidação) na escola que atua, o(a) docente respondeu: Não muito, às vezes brincadeiras de alunos, mas que não eram levadas a sério.

Pela ótica do(a) professor(a) colaborador(a), a violência escolar expressa no bul- 
lying não passa de mera brincadeira que não precisa ser considerada como algo sério. A indistinção entre a prática do bullying e as "brincadeiras" mostra, em primeiro lugar, a existência dessa violência escolar e, portanto, do preconceito que é a base de tudo, ademais, a não distinção não oferece abertura para a percepção da necessidade da interferência, $e$ isso fica expresso pela não consideração das "brincadeiras" como algo com que tenhamos de nos preocupar. Essa visão, segundo Crochík (2014), revela negação e insensibilidade em relação às suas ocorrências, revela o descuido para com a formação da consciência moral e da cultura nos alunos, e o descuido para com as possíveis sequelas que se assentam sobre essa prática, como os prejuízos psíquicos, por exemplo. Essa visão marca também a indiferença sobre toda a situação de violência escolar $e$ sobre as partes envolvidas, e ignorar o conflito e o sofrimento alheio se configura em uma forma de preconceito, além de reproduzir e de reforçar essa irracionalidade e de não oferecer condições para a busca das causas e de soluções para o problema. Encarar a violência escolar no bullying como "brincadeiras" entre as crianças e os adolescentes seria o mesmo que entendê-la como natural, e não levá-las a sério suscita o pensamento de que os próprios envolvidos de- vem se resolver e/ou superar sem a necessidade de interferência do adulto, conforme explica Crochík (2014), inclusive para "aprenderem a lidar com os problemas da vida", sendo que, de um lado, estariam os agressores se adequando à ideologia do mais apto e do mais forte, e de outro, a vítima que precisaria se impor e se igualar para também se adaptar a essa ideologia, como se os valores do desempenho e da competência precisassem imperar sobre os valores e os direitos humanos.

A segunda questão se referiu aos motivos pelos quais o bullying ocorre. Como resposta, o(a) professor(a) afirmou: Por simples displicência dos alunos, às vezes, por rebeldia ou por quererem se destacar dentro da sala de aula ofendendo os demais (amigos da própria sala).

A palavra displicência que aparece na resposta do(a) colaborador(a) é um termo polissêmico; no entanto, diante do contexto, o que se pôde apreender do possível sentido de sua utilização revela que, na visão do(a) professor(a), o aluno provocador apresenta imaturidade, falta de compromisso ou desatenção quanto às regras, por exemplo. $\mathrm{Na}$ perspectiva do(a) professor(a), a causa da violência escolar no bullying está no aluno agressor, ou seja, este seria o único culpado, como uma responsabilidade individual $e$ 
independente das condições da sociedade administrada. Segundo Crochík (2014), isso expressa uma visão idealista sobre a situação por prescindir o indivíduo da realidade, $e$ também expressa um desconhecimento sobre a organização da sociedade atual, sociedade esta que fomenta a violência por se pautar na ideologia da competência e do desempenho individual na formação de seus membros. De acordo com a perspectiva do(a) colaborador(a), a rebeldia indica que os alunos agressores não apresentam autonomia e formação de consciência moral frente à autoridade. Já o fato de quererem se destacar dentro da sala de aula demonstra a necessidade de ocuparem a posição superior na hierarquia escolar, isto é, de serem populares, notados e reconhecidos pela força $e$ aptidão física, tudo isso pela ofensa que é uma forma de violência manifesta também expressa na resposta do(a) professor(a). Ambas as situações são explicadas por Crochík (2014).

Sobre as duas perguntas que se referem às características dos agressores $e$ das vítimas, o(a) colaborador(a) informou: Agressores: Às vezes são alunos bagunceiros, que não respeitam os colegas e os professores, muitos são repetentes e não têm acompanhamento da familia na escola. Vítimas: São na maioria das vezes quietos, aqueles que apresentam alguma característica diferente daquele que ofende: são gordos, negros, especiais.

As respostas convergem com as explicações de Crochík (2014), pois o fato de os agressores serem bagunceiros e de não respeitarem ninguém demonstra que esses não apresentam obediência às regras, autonomia $e$ formação da consciência moral diante da autoridade. O fator repetência demonstra que os provocadores possivelmente sejam incitados pela ideologia do desempenho corporal em detrimento do intelectual. Neste sentido, de acordo com Crochík (2011; 2014), por formação reativa frente ao próprio fracasso escolar, a ocorrência da agressão pode se dar sobre os indivíduos que apresentam o que os agressores almejam, porém, não conseguem, isto é, o desempenho intelectual que justamente representa aos provocadores a fragilidade que valorizam, mas desprezam, onde a força deve superar a inteligência como um modelo de contraposição para a adaptação. Sobre a ausência dos pais na vida acadêmica do agressor, que foi outro aspecto levantado na resposta, demonstra que o comportamento violento possa também estar relacionado com o processo de negligência da parte dos pais para com o filho, o que não deixa de ser uma violência, logo, o aluno passa de vítima 
(ignorado) para agressor (adaptado). Assim, o provocador executa a autoridade pela força para intimidar, agredir e ofender como mecanismos para obtenção do poder e da posição superior da hierarquia social que também está presente na escola e nos lares (CROCHÍK, 2014).

No que se refere à caracterização das vítimas, estas para o(a) professor(a) são quietas, o que indica possível passividade $e$ rebaixamento da auto-estima ou apatia, o que pode ser, inclusive, consequência do sofrimento no bullying, pois, Crochík (2014) informa sobre os prejuízos psíquicos que esse tipo de violência pode demandar. A resposta também suscita o pensamento de que as vítimas são indivíduos que apresentam características diferenciadas do exigido padrão da sociedade que se relaciona com o desempenho intelectual e o corporal, e que justamente por esse motivo se tornam alvo dos adaptados com a coletividade. Os provocadores contrapõem a diferenciação como reação diante da fragilidade por identificação negativa, processo já explicado no parágrafo anterior, $e$ isso se manifesta pelo preconceito que, por sua vez, é uma forma de violência. $\mathrm{O}(\mathrm{A})$ professor(a) também pontuou que as vítimas são os gordos, os negros e os "especiais", exatamente alguns dos grupos minoritários destacados nas recentes pesquisas
(ANTUNES; ZUIN, 2008 apud CROCHÍK, 2014) que afirmam que as vítimas são pessoas com alguma diferenciação física, socioeconômica, étnica, de preferência sexual e de deficiência física, sensorial ou intelectual. As vítimas citadas na resposta são, portanto, os alunos que já estavam na escola regular e os que estão em situação de inclusão, logo, não se detectou nenhuma desproporção nesse sentido.

Sobre a quinta pergunta, referente aos alunos em situação de inclusão serem ou não alvos de bullying na mesma proporção que os outros alunos, a resposta foi a seguinte: Não vejo muito isso, mas, já ouvi falar que acontece bullying com esses tipos de alunos.

Com essa resposta tão lacônica $e$ aparentemente vazia, o(a) colaborador(a) parece ser indiferente e praticamente ignora o bullying cometido contra alunos em situação de inclusão. As expressões "já ouviu falar" e "esses tipos de alunos" indicam certo distanciamento do(a) profissional com alunos em situação de inclusão e/ou com a vitimização desses alunos no bullying. Essas atitudes, com base na negação, provavelmente, se configuram como o próprio preconceito sutil contra esse alunado, inclusive fomentando a reprodução dessa racionalidade. 
A sexta e última pergunta se referiu ao que seria necessário fazer para combater esse tipo de violência na escola, e sobre o papel das autoridades a este respeito. Primeiramente conscientizar a sala de aula, a escola, de que o papel principal destes é trabalhar com o diferente sem discriminá-lo. Tentar "minimizar" as diferenças dentro da sala de aula. Segundo, seria criar leis ou estatutos mais severos com esse tipo de atitude, punir o ofensor e dar mais respaldo para o ofendido.

A resposta mostra um intento de homogeneização e não reconhecimento das particularidades individuais, pois a expressão “'minimizar' as diferenças” infere que sejam diminuídas as especificidades e cada vez mais igualados os sujeitos em uma forma de padrão corporal e intelectual. $\mathrm{O}(\mathrm{a})$ colaborador(a) deixou bastante clara sua visão idealista e legalista, pois enfatiza a culpabilização do agressor e a necessidade de sua punição, além disso, ele(a) afirma que deveria haver leis e estatutos mais severos para evitar a violência na escola. Essa posição concerne, segundo Crochík (2014), ao grupo de indivíduos que acredita que o agressor deve ser responsabilizado pelos seus próprios atos, mas sem considerar as influências da organização da sociedade, e que deve receber as consequentes represálias por tê-los cometido para sua própria remissão. Para o(a) professor(a), o importante seria haver leis e estatutos mais severos contra a violência, mas não mencionou sobre a necessidade de foco na formação da autonomia e da consciência moral dos alunos, apenas apontou sobre a criação de um aparato técnico que deve ser introjetado de maneira heterônoma por eles.

\section{Considerações Finais}

Em linhas gerais, as respostas do(a) professor(a) colaborador(a) convergem com os estudos de Crochík (2014) sobre a violência escolar no bullying e com as conjecturas que podem ser extraídas da Teoria Crítica da Sociedade sobre o impacto da racionalidade tecnológica tanto nos atos de violência escolar, quanto na concepção e no comportamento do(a) professor(a) sobre essa temática.

A negação do(a) colaborador(a) ficou bastante clara pela sua percepção do bullying como uma "brincadeira", o que demonstra a indiferenciação pelo predomínio da racionalidade instrumental e de seus reflexos na formação "subjetiva" do indivíduo. Outro aspecto que aparece com intensidade refere-se a sua falta de percepção ou de conhecimento sobre as condições da sociedade atual, inclusive culpando o agressor por seus atos violentos, prescindindo tanto a escola 
quanto os alunos dessa realidade e não contribuindo para a formação da consciência moral e da autonomia dos alunos. Apesar de declarar que não testemunhou o bullying, mas sim "brincadeiras", o(a) professor(a) mencionou características para o agressor relacionadas à falta de autonomia e da consciência moral, e ainda, à ideologia da hierarquia escolar; já para a vítima, ele(a) relacionou suas características ao aspecto da homogeneização social. Por último, mas não menos importante, uma das respostas dei- xou evidente a presença e a reprodução do preconceito diante dos alunos em situação de inclusão.

Assim, reitera-se o entendimento de que há o predomínio da racionalidade tecnológica na concepção e nos atos educativos por parte do(a) docente. Como explica Adorno (1995), a educação faz parte da sociedade administrada e tem sua estrutura organizada como tal.

\section{Referências}

ADORNO, Theodor. (1967). Educação e Emancipação. Rio de Janeiro: Paz e Terra, 1995.

CROCHÍK, José Leon. Teoria Crítica da Sociedade e Psicologia: alguns ensaios. São Paulo: Araraquara; Brasília: Junqueira \& Marin, 2011.

CROCHÍK, José Leon. Projeto Violência Escolar: discriminação, bullying e responsabilidade. São Paulo: Universidade de São Paulo, 2014.

MARCUSE, Herbert. (1955). Eros e Civilização: uma interpretação filosófica do pensamento de Freud. Rio de Janeiro: Zahar, 1975. 